\title{
Association of Death Anxiety and Quality of Life in the Caregivers of Patients with Multiple Sclerosis
}

\author{
Mahnaz Seyedoshohadaee ${ }^{1}$, Maryam Bozorgi Matin ${ }^{2}$, Hamid Haghani ${ }^{3}$
}

\begin{abstract}
Background \& Aims: Multiple sclerosis (MS) is a disease that evolves into a chronic progressive phase and leads to a loss of muscular ability following the attack of the nervous system by the immune system. MS incidence has significantly increased in Iran and the world, and its disabling and progressive nature has affected various aspects of the life of patients and their caregivers. In fact, caregivers face the process of death, pain, and fear of mortality of patients during the care process, which may affect their quality of life. Therefore, given the direct impact of the caregivers' quality of life on patients' quality of life, more support of caregivers is of utmost importance. Since the care of patients might cause death anxiety and decrease the quality of life of caregivers, the present study aimed to determine the relationship between death anxiety and the quality of life of caregivers of MS patients.

Materials \& Methods: This descriptive and correlational study was performed on caregivers of MS patients who referred to Iran MS society in 2018. In total, 200 individuals were selected by convenience sampling after determining the sample size based on $95 \%$ confidence interval, $80 \%$ test power, and 0.2 correlation coefficient between death anxiety and quality of life of MS patients. The research was approved by the ethics committee of the Iran University of Medical Sciences. Data were collected using a demographic characteristics questionnaire for caregivers of MS patients (age, gender, level of education, marital status, economic status, occupational status, relationship with the patient, duration of care, and being responsible for care alone), the 36-item short-form health survey (SF-36), and Templer's death anxiety scale. The latter instrument encompassed 15 items and was scored in a range of 0-15. In this regard, a score higher than eight was indicative of high death anxiety in the participants, whereas scores below seven showed low death anxiety. On the other hand, SF36 had eight dimensions of general health, physical performance, role limitations due to physical issues, role limitations due to emotional reasons, physical pain, social performance, joy, and psychological health. In the mentioned questionnaire, the lowest and highest scores were zero (worst case scenario) and 100 (best case scenario), respectively. In the end, higher scores demonstrated a better quality of life. Data analysis was performed n SPSS version 16 using descriptive (frequency, frequency percentage, mean and standard deviation) and inferential (analysis of variance, independent t-test, Scheffe's test, and Pearson's correlation coefficient) statistics.

Results: In this study, the mean age of the participants was $40.39 \pm 11.75$ years. The majority of the participants were male $(58.5 \%)$ and married $(64.4 \%)$. In terms of relationships with patients, $40 \%$ of the subjects were spouses of the patients, and $54.5 \%$ of them took care of the patients alone. The mean duration of patient care was $8.7 \pm$ 5.9 , and most caregivers had a diploma degree (36.2\%). Regarding residential status, $58.3 \%$ of the subjects had personal homes, and $44.2 \%$ of the participants had government jobs and a moderate economic status. In addition, about half of the people $(50.8 \%)$ had social security insurance, and $54.5 \%$ of caregivers took care of the patients alone. According to the results, the mean death anxiety and quality of life scores of caregivers were estimated at $5.92 \pm 3.82$ and $55.42 \pm 14.82$, respectively. Moreover, 143 subjects $(71.5 \%)$ received a low death anxiety score (in the range of zero-seven) while 57 of them (28.5\%) a high score (above eight) in this respect. In the study of caregivers' quality of life, the highest and lowest mean and standard deviation were obtained in terms of physical performance and role limitations due to emotional reasons, respectively. The results showed a moderate quality of life in caregivers, and a significant, reverse correlation between death anxiety and quality of life $(r=0.42)$

1. Instructor, Nursing Care Research Center, Department in Internal-Surgical Nursing, School of Nursing and Midwifery, Iran University of Medical Sciences, Tehran, Iran

${ }^{2}$. MS Student in Nursing, Department of Medical-Surgical Nursing, School of Nursing and Midwifery, Iran University of Medical Sciences, Tehran, Iran (Corresponding author) Tel: +98-9038228272 Email: mbozorgimatin@gmail.com 3. Instructor, Department of Biostatistics, School of Health, Iran University of Medical Sciences, Tehran, Iran
\end{abstract}


$(\mathrm{P}<0.05)$. In addition, there was a significant association between death anxiety and the variables of relationship with the patient $(\mathrm{P}=0.001)$, duration of care $(\mathrm{P}=0.036)$, occupational status $(\mathrm{P}=0.021)$, and type of insurance $(\mathrm{P}=0.006)$. Furthermore, a significant relationship was found between quality of life and the variables of age $(\mathrm{P}=0.032)$, level of education $(\mathrm{P}<0.001)$, income level $(\mathrm{P}<0.001)$, occupational status $(\mathrm{P}<0.001)$ and insurance $(\mathrm{P}<0.001)$.

Conclusion: According to the results of the study, the majority of caregivers had low death anxiety. In addition, the mean score of death anxiety was estimated at 5.92 (out of 15), which demonstrated low death anxiety in these individuals. The results were indicative of a reverse correlation between death anxiety and quality of life and its dimensions. In other words, an increase in death anxiety led to a decrease in quality of life and its dimensions. Given the significant correlation between death anxiety and quality of life, it is recommended that more support be provided by healthcare providers to eliminate problems and decrease death anxiety in caregivers, especially those taking care of MS patients. Given the progressive nature of MS and its psychological outcomes, caregivers of these patients need ongoing psychological training to help them care for patients more effectively. Therefore, it is suggested that programs be designed to help caregivers and improve their quality of life in line with focusing on themselves and their needs. It is also recommended that more attention be paid to the importance of care and caregivers in the field of nursing management and continuous nursing education. It is also important to focus on the problems and disabilities of patients and their caregivers. For further research, it is suggested that the quality of life of caregivers be compared with the quality of life of patients and death anxiety in caregivers with death anxiety in patients.

\section{Keywords: Multiple Sclerosis, Caregivers of Patients, Quality of Life, Death Anxiety}

\section{Conflict of Interest: No}

How to Cite: Seyedoshohadaee M, Bozorgi Matin M, Haghani H. Association of Death Anxiety and Quality of Life in the Caregivers of Patients with Multiple Sclerosis. Iran Journal of Nursing. 2019; 32(120):1-13.

Received: 3 Jul 2019

Accepted: 5 Oct 2019 


\title{
ارتباط بين اضطراب مر تى و كيفيت زندكى مرتبط با سلامت در مراقبين بيماران مبتلا به مالتييل اسكلروزيس
}

\author{
مهناز سيدالشهرايى '، مريم بزرتى متين '، حميد حقانى"
}

زمينه و هدف: ماهيت ييشرونده و ناتوان كننده بيمارى مالتيبل اسكلروزيس (MS) ابعاد مختلف زندكى بيمار و مراقبين را تحت تأثير قرار مىدهد.

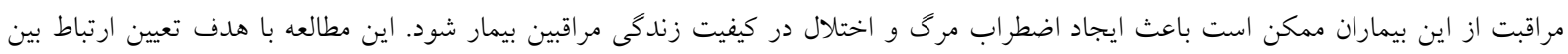

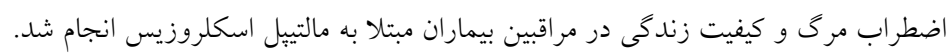

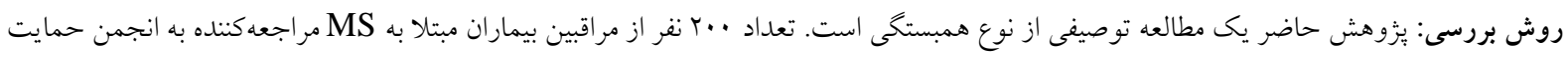

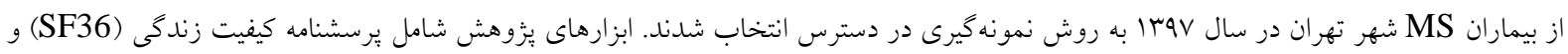

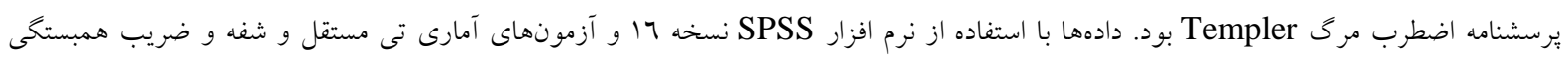
ييرسون مورد تجزيه و تحليل قرار گرفت.

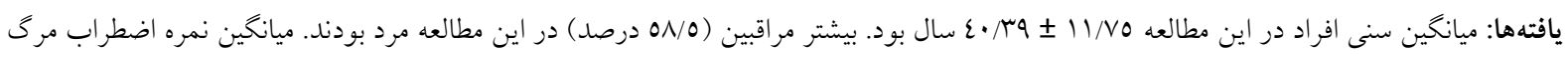

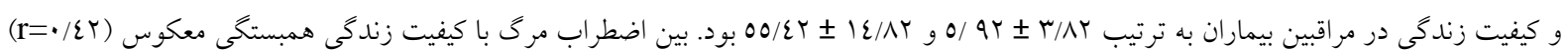

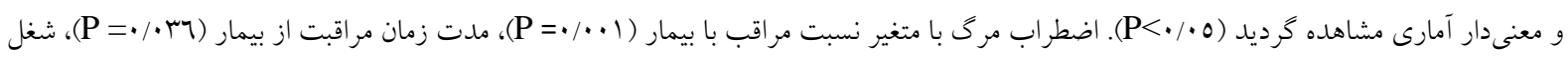

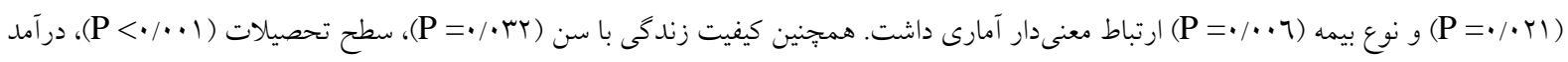

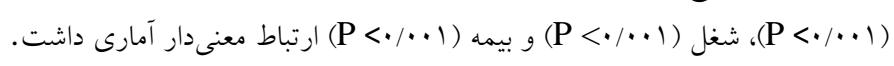

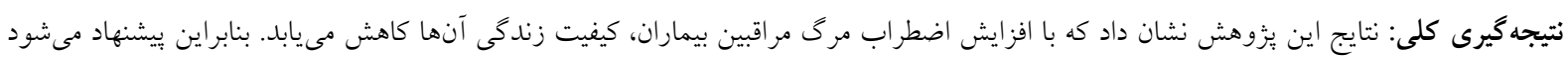

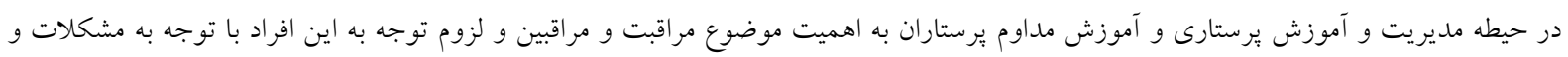

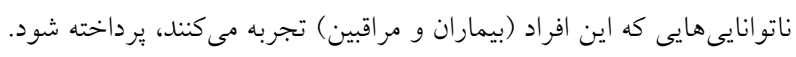
كليد وازهها: مالتيبل اسكلروزيس، مراقبين بيماران، كيفيت زندگى، اضطراب مرگ تعارض منافع: ندارد تاريخ دريافت:

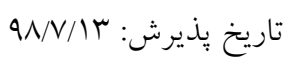

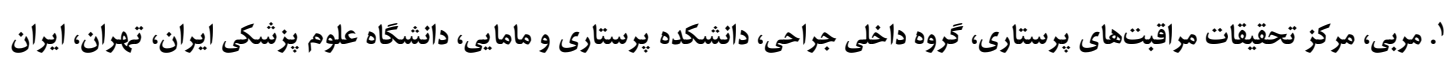

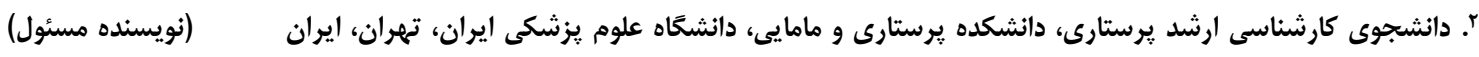
:Email: mbozorgimatin@gmail.com

شماره تماس: ‘. مربى، كروه أمار زيستى، دانشكده بهداشت، دانشكاه علوم يزشكى ايران، تهران، ايران 
Sى كنند r T نفر براى مشكل اضطراب به يزشك مراجعه

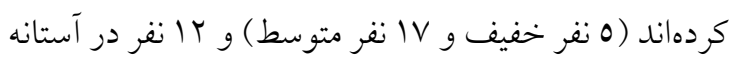
افسردگى بودند (ع نفر خفيف و 1 نفر متوسط). به علاوه

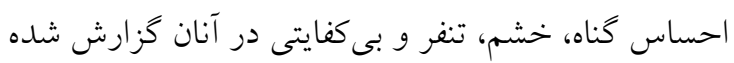

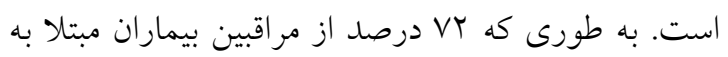
MS

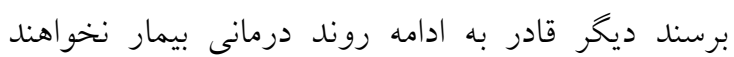

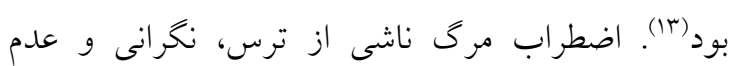

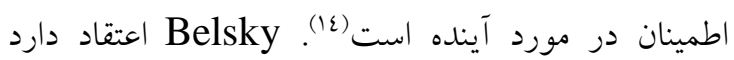

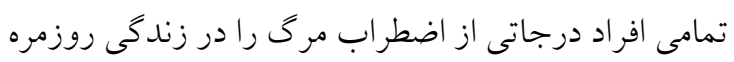
تجربه مى كنند اما طيف گستردهاى از عوامل نظير سن، جنسيت، مذهب، عوامل فرهنكى و اجتماعى باعث مى شود ميزان اضطر اب مرى در افراد متفاوت باشد (10).

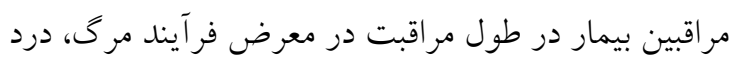

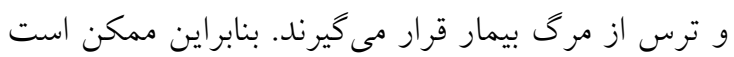

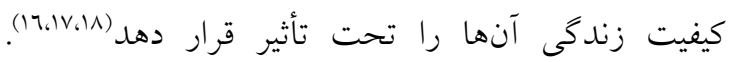

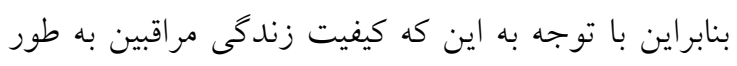

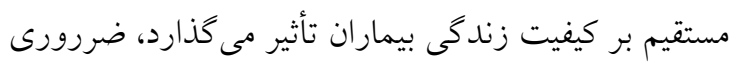

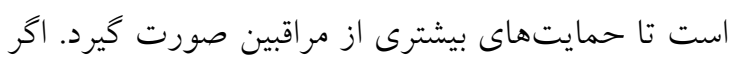
جه مطالعات بسيارى در زمينه بيمارى MS و و يا بيماران مبتلا به اين بيمارى انجام شده است (19) اما اطلاعات بسيار

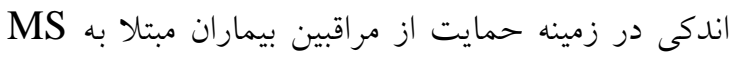

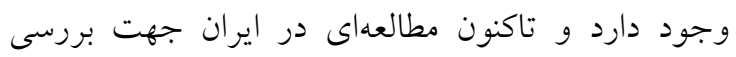

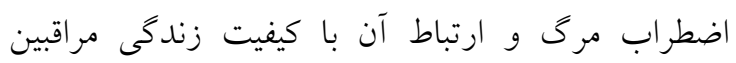

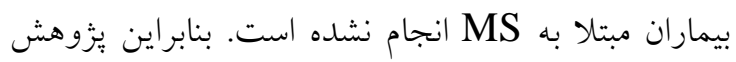

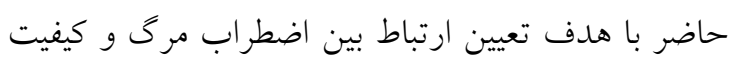
زندكى در مراقبين بيماران مبتلا به MS انجام شده است.

\section{روش بررسى}

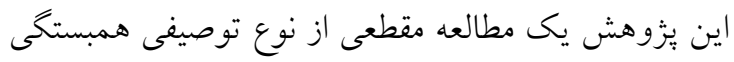

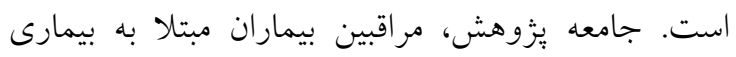

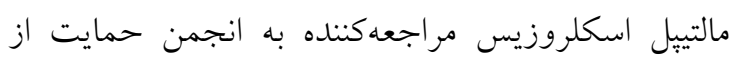

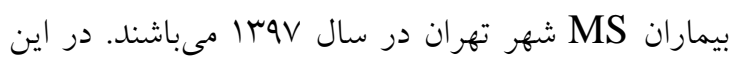

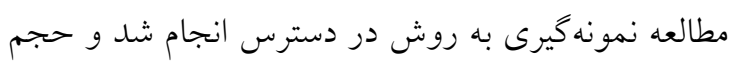

\section{مقدمه}

مالتيبل اسكلروزيس يا MS يك اختلال مزمن و بيشرونده

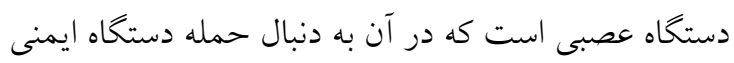
به سيستم عصبى، به تدريج عضلات توانايى خود ران از از دست مىدهند (1). علائم مختلف اين بيمارى عبارتند از بـاز

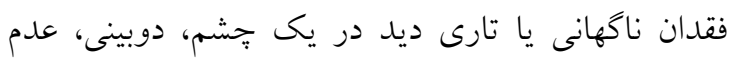

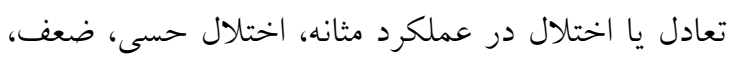

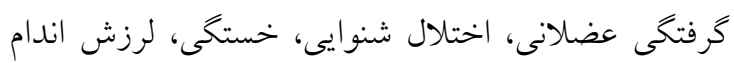

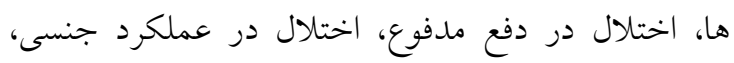

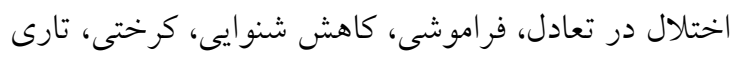

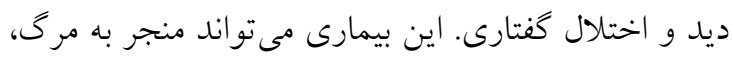

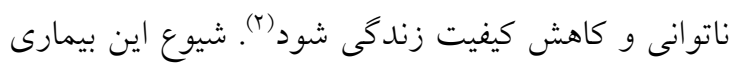

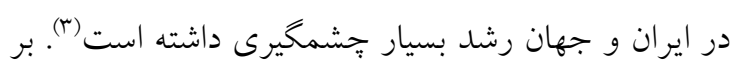

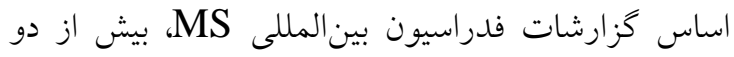

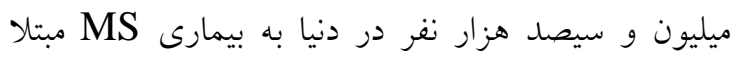

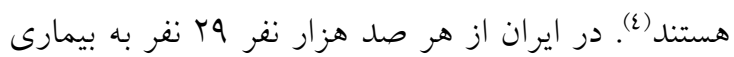
MS مبتلا هستند (0)

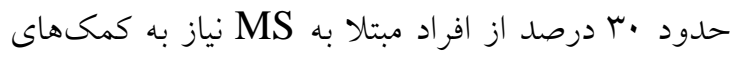

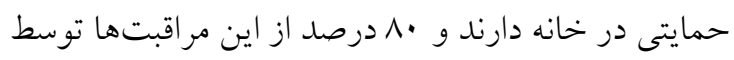

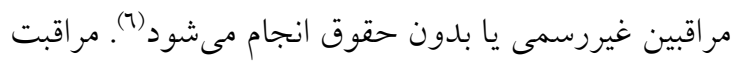

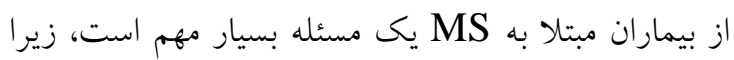

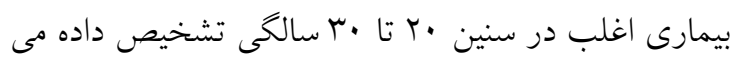

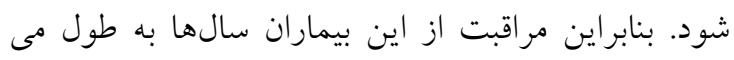

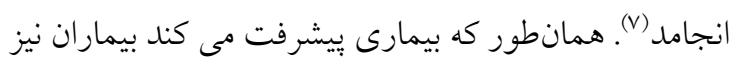

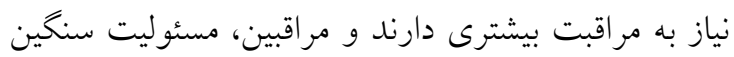

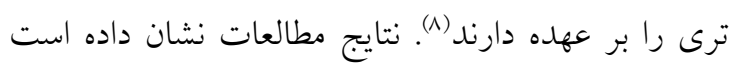

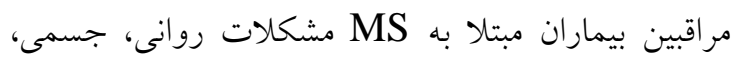
اجتماعى و اقتصادى بسيارى را در طول مراقبت تجربه مى

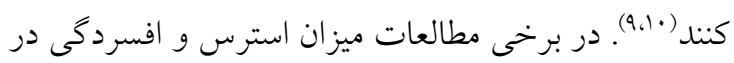
مراقبين بيماران مبتلا به MS نسبت به ساير مر اقبين بيشتر

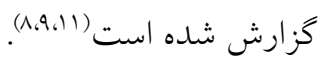
يكى از مسائلى كه مراقبين بيماران با آن مو اجهاند اضطراب

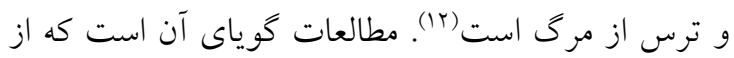

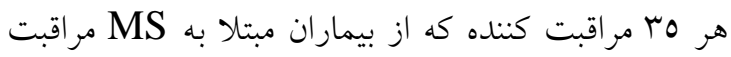


كرفته است (Yr). نسخه فارسى آن نيز توسط منتظرى و

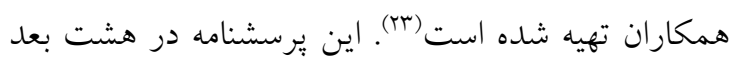

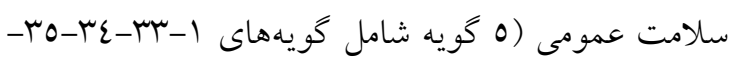

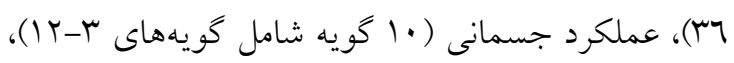

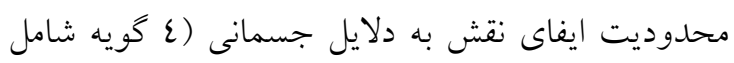

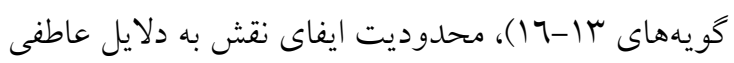

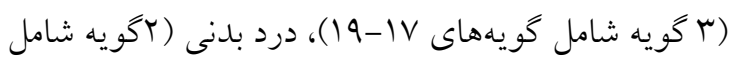

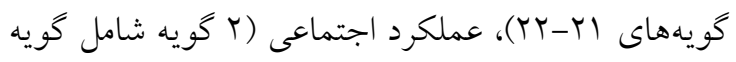

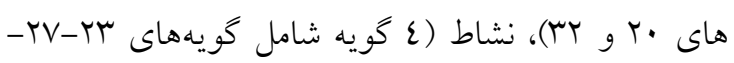

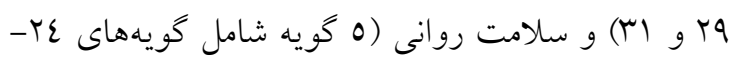

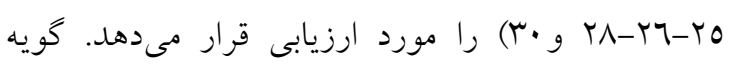

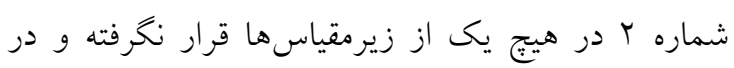

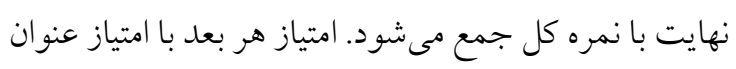

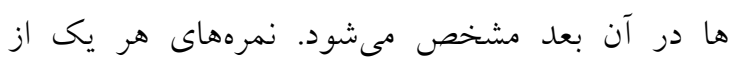
زيرمقياسها جداكانه حساب و ميانخين كرفته مىشود. نمره به دست آمده به عنوان درصد ميزان سلامتى در آن آن بعد است. براى محاسبه نمره كل برسشنامه مجموع اعداد

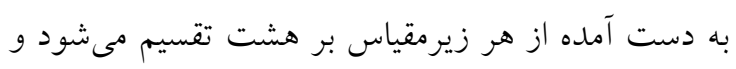

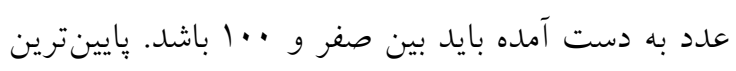

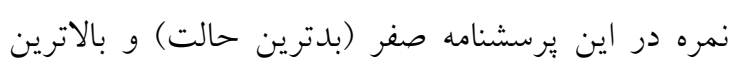
نمره . إ (بهترين حالت) است. در نهايت نمره بالاتر نشان دهنده كيفيت زندكى بهتر بود. هِ از اخذ رضايت نامه كتبى و با توجه به معيارهاى ورود

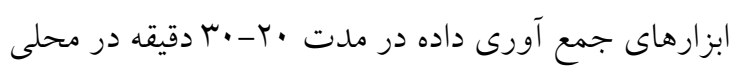

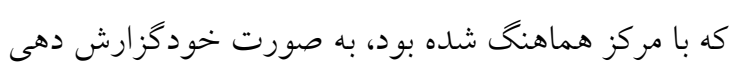

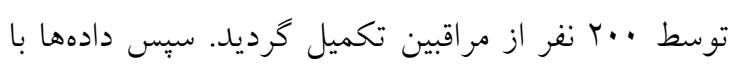

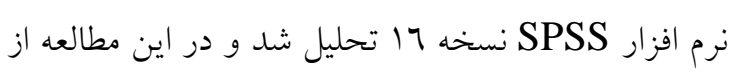

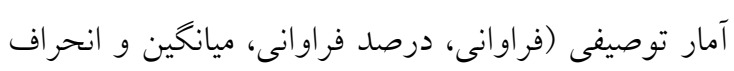

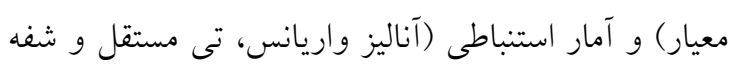
و ضريب همبستكى بيرسون) استفاده شد.

\section{يافتهها}

در مطالعه حاضر .r مراقب مورد بررسى قرار كرفتند.

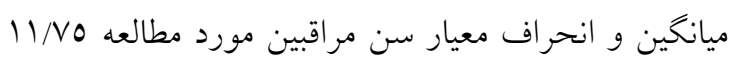

نمونه بر اساس سطح اطمينان 90 درصد و توان آزمون

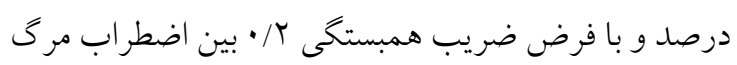

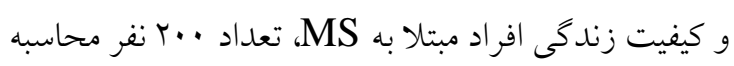
شد. مطالعه حاضر مجوز كميته اخلاق دانشكاه علوم

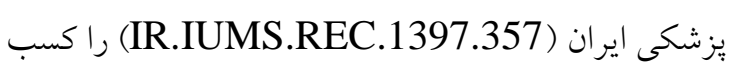
نموده است. ابزار جمع آورى داده عبارت بودند از:

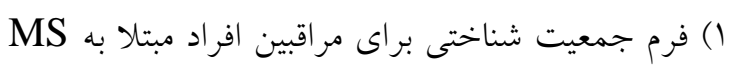

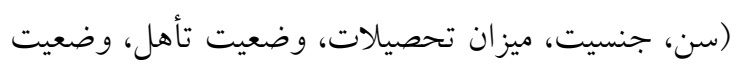

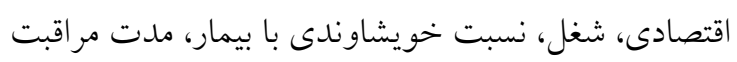

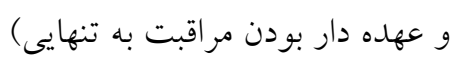

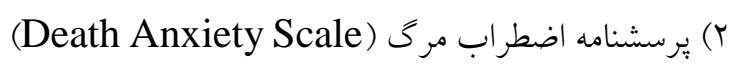
كه توسط Templer طر احى و در سال • 19V منتشر شده

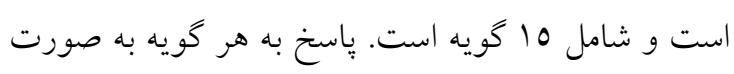

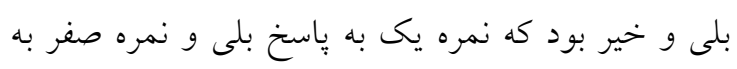

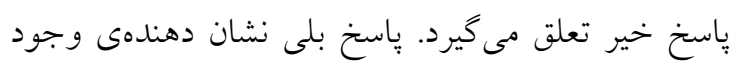

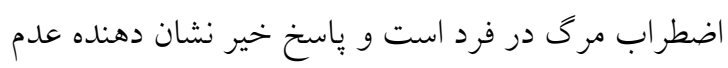

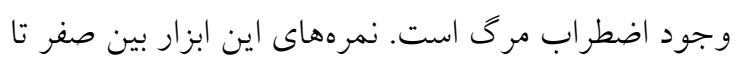

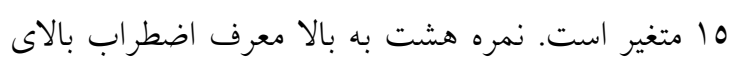

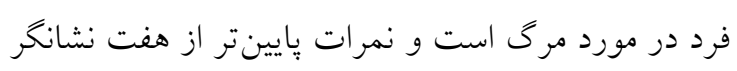

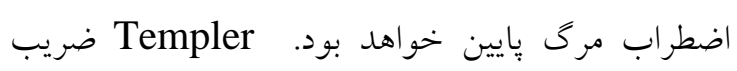

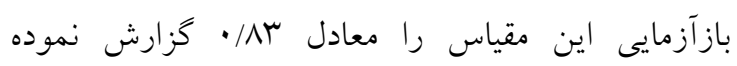

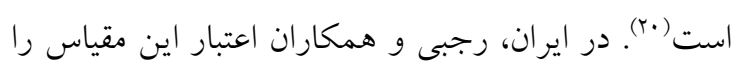
مورد بررسى قرار داده و ضريب اعتبار تصنيفى را معادل

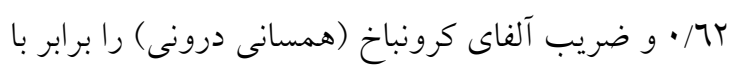

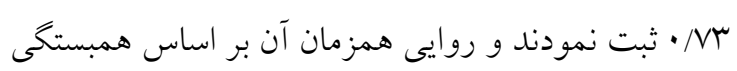

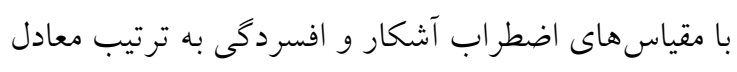

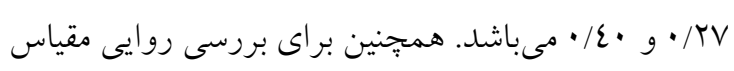

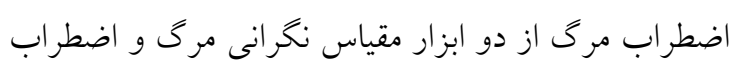

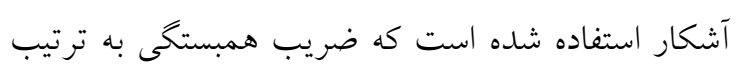

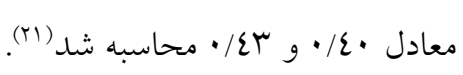

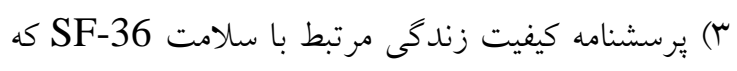
توسط Wherbon و Whar طراحى شده است و اعتبار و بايايى آن در كروههاى مختلف بيماران مورد بررسى قرار 


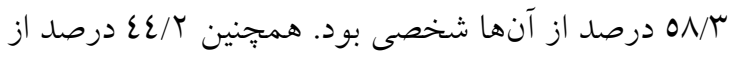
مراقبين داراى شغل دولتى بودند و شرايط اقتصادى خود را متوسط كزارش كردند. نزديك به نيمى از افراد يعنى

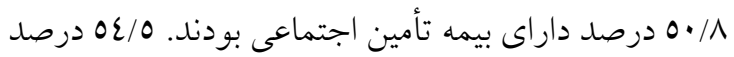
از مراقبين اعلام كردند به تنهايى از فرد بيمار مراقبت مى

كنند (جدول شماره (1).

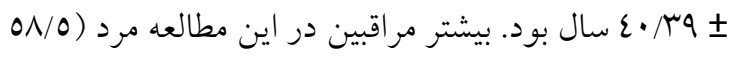

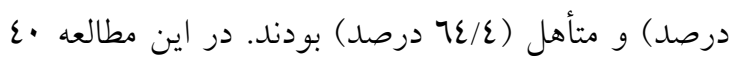
درصد از مراقبين، همسر بيمار بودند و مراقبين به تنهايى از فرد بيمار مراقبت مىكردند. مدت مراقبت از بيمار به طور متوسط 0/9 \ 1/V بود. بيشتر

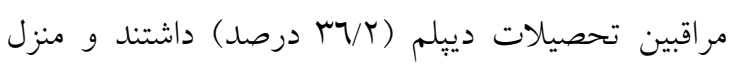

جدول شماره ا: توزيع فراوانى مشخصات جمعيت شناختى مراقبين بيماران مبتلا به مولتيبل اسكلروزيس شهر تهران، وجسان

\begin{tabular}{|c|c|c|c|}
\hline ل درصد & فر اوانى & & مشخصات جمعيت شناختى \\
\hline r. & $\varepsilon$. & كمتر از ·r & \\
\hline ro/o & vi & rq-r. & \\
\hline$T r / 0$ & ¿o & $\varepsilon q-\varepsilon$. & سن (سال) \\
\hline $1 T / 0$ & ro & $09-0$. & \\
\hline $9 / 0$ & 19 & $V \cdot-7$. & \\
\hline \multicolumn{2}{|c|}{$\varepsilon \cdot / r q \pm 11 / v_{0}$} & انحر اف معيار 土 ميانخين & \\
\hline \multicolumn{2}{|c|}{$r \cdot-V \cdot$} & بيشينه-كمينه & \\
\hline $0 N / 0$ & $11 \mathrm{~V}$ & مرد & جنسيت \\
\hline$\varepsilon 1 / 0$ & $\lambda r$ & ز - ان & \\
\hline$r / 0$ & v & يدر & \\
\hline 1. & r. & مادر & \\
\hline $1 \cdot 10$ & r & خواهر & \\
\hline $1 \cdot 10$ & r) & 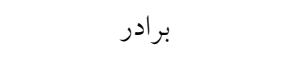 & 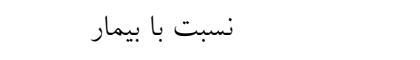 \\
\hline$\varepsilon$. & $\wedge \cdot$ & 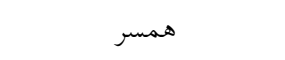 & \\
\hline $1 \% / 0$ & rV & 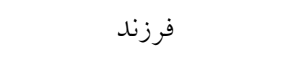 & \\
\hline ir & $r \varepsilon$ & 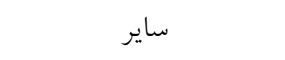 & \\
\hline v & $1 \varepsilon$ & كمتر از يك & \\
\hline rt & $\varepsilon \varepsilon$ & $1-\varepsilon$ & \\
\hline$r V / 0$ & 00 & $0-9$ & مدت مراقبت از بيمار (سال) \\
\hline$r \varepsilon / 0$ & $\varepsilon 9$ & $1 \cdot-1 \varepsilon$ & \\
\hline 19 & rی & ا 10 و بيشتر & \\
\hline & & انحر اف معيار 土 ميانخين & \\
\hline & & بيشينه-كمينه & \\
\hline$r 9 / 7$ & 09 & زير دييلم & \\
\hline$r y / r$ & Vr & دييلم & تحصيلات \\
\hline$r \varepsilon / r$ & $u$ & دانشخاهى & \\
\hline r. & $\varepsilon$. & ضعيف & درآمد \\
\hline VN/O & $10 \mathrm{~V}$ & 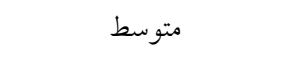 & \\
\hline $1 / 0$ & $r$ & خوب & \\
\hline
\end{tabular}




\begin{tabular}{|c|c|c|c|}
\hline $0 \Lambda / r$ & 117 & شخصى & \\
\hline$\varepsilon \cdot / r$ & $\wedge$. & اجاره اي & نوع مالكيت منزل \\
\hline $1 / 0$ & r & خوابگاه & \\
\hline$\varepsilon \varepsilon / r$ & $\Lambda$ & كارمند & \\
\hline$r V / T$ & 00 & آزاد & \\
\hline $1 \pi / 1$ & r & بيكار & شغل \\
\hline $10 / 1$ & $r$. & خانه دار & \\
\hline$r T / 7$ & 0. & مجرد & \\
\hline $7 \varepsilon / \varepsilon$ & $|r|$ & 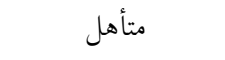 & وضعيت تأهل \\
\hline $9 / 1$ & IV & مطلقه / بيوه & \\
\hline$\varepsilon / 0$ & Ir & ندارد & \\
\hline $17 / 7$ & Tr & خدمات درمانى & \\
\hline V & $1 \varepsilon$ & 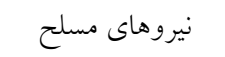 & \\
\hline$r \cdot / 1$ & $\varepsilon$. & بيمه سلامت & نوع بيمه \\
\hline 0.11 & 1.1 & بيمه تامين اجتماعى & \\
\hline 1 & r & ساير & \\
\hline $0 \varepsilon / 0$ & $1 \cdot 1$ & بله & به تنهايى مراقبت كردن از بيمار \\
\hline$\varepsilon 0 / 0$ & 94 & خير & \\
\hline
\end{tabular}

است. بنابراين سطح كيفيت زندكى در مراقبين در سطح متوسط مىباشد (جدول شماره Y).

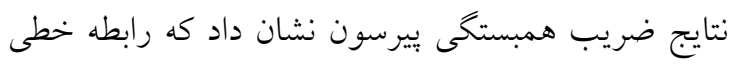

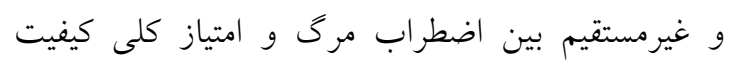

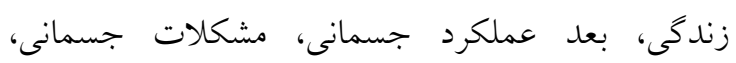
مشكلات هيجانى، انرزى و نشاط، سلامت عاطفى، عملكرد

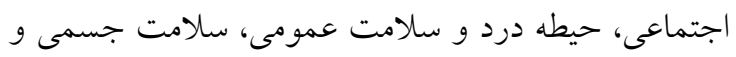

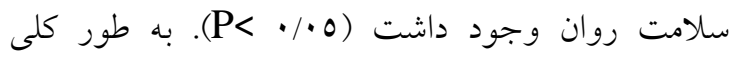

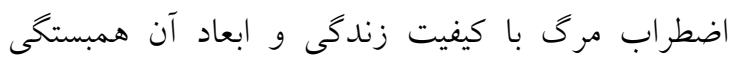

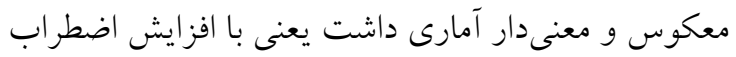

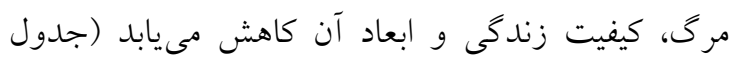

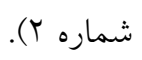

نتايج بررسى سطح اضطراب در بين مراقبين نشان داد كه

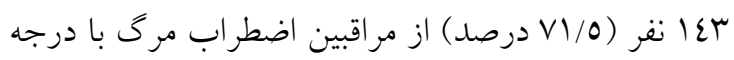

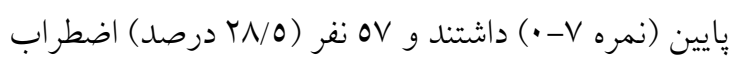

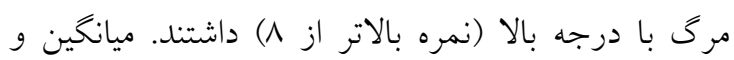

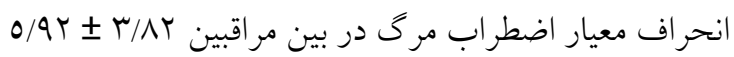
در بررسى سطح كيفيت زندكى مر اقبين، بالاترين و بايين

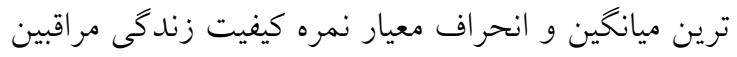
به ترتيب در بعد عملكرد جسمانى و محدوديت ايفاى نقش ونش

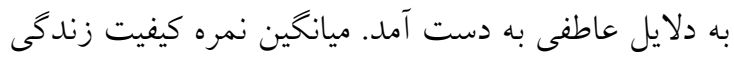

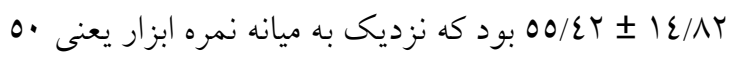


جدول شماره r: شاخصهاى عددى و همبستكى كيفيت زندكى مرتبط با سلامت در مراقبين مبتلايان به مالتيبل اسكلروزيس با اضطراب

\begin{tabular}{|c|c|c|c|c|c|c|}
\hline \multicolumn{2}{|c|}{ نتيجه آزمون همبستحى به اضطراب مرى } & \multirow{2}{*}{ 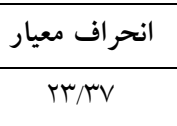 } & \multirow{2}{*}{$\begin{array}{l}\text { ميانگيv } \\
\text { VE/OV }\end{array}$} & \multirow{2}{*}{ بين } & \multirow{2}{*}{ كمينه } & \multirow{2}{*}{ كيفيت زندكى و حيطههاى آن } \\
\hline$r=-\cdot / r 9$ & $\mathrm{P}<\cdot / \cdot \cdot 1$ & & & & & \\
\hline$r=-\cdot / T V$ & $\mathrm{P}<\cdot / \cdot \cdot 1$ & rq/qr & $r \cdot \mu_{\Lambda}$ & $1 \ldots$ & $\cdot$ & محدوديت ايفاى نقش به دلايل جسمانى \\
\hline$r=-\cdot / r 7$ & $\mathrm{P}<\bullet / \cdot \cdot 1$ & $\sum 1 / \wedge \uparrow$ & $r \cdot \mu_{1}$ & $1 .$. & . & محدوديت ايفاى نقش به دلايل عاطفى \\
\hline$r=-\cdot / r r$ & $\mathrm{P}<\cdot / \cdot \cdot 1$ & $17 / 4$ & $\Delta \vee / \Lambda$ & $1 .$. & 1. & انرزى و نشاط \\
\hline$r=-\cdot / r r$ & $\mathrm{P}<\bullet / \cdot \cdot 1$ & $14 / .7$ & $09 / 70$ & $1 .$. & r^ & سلامت عاطفى \\
\hline$r=-\cdot / r r$ & $\mathrm{P}<\cdot / \cdot \cdot 1$ & $r T / \Omega$ & $\eta / r \varepsilon$ & $1 .$. & $1 T / 0$ & عملكرد اجتماعى \\
\hline$r=-\cdot / r 0$ & $\mathrm{P}<\cdot / \cdot \cdot 1$ & $r \varepsilon / V I$ & $V T / N 7$ & $1 \ldots$ & $1 r / 0$ & درد \\
\hline$r=-\cdot / r)$ & $\mathrm{P}<\bullet / \cdot \cdot 1$ & $10 / 0 \varepsilon$ & $\varepsilon 9 / 09$ & 10 & $\cdot$ & سلامت عمومى \\
\hline$r=-\cdot / \varepsilon$ & $\mathrm{P}<\cdot / \cdot \cdot 1$ & $17 / 9 r$ & OV/Tr & qr/vo & $N / T$ & سلامت جسمى \\
\hline$r=-\cdot / r q$ & $\mathrm{P}<\cdot / \cdot \cdot 1$ & $10 / r \Lambda$ & $0 \varepsilon / .0$ & $\Lambda 7 / \Gamma_{0}$ & $\mid r / 7 r$ & سلامت روانى \\
\hline $\mathrm{r}=-\cdot / 2 \mathrm{r}$ & $\mathrm{P}<\cdot / \cdot \cdot 1$ & $1 \varepsilon / \Lambda T$ & $00 / 2 r$ & 19 & $1 \cdot \mu^{\wedge}$ & كيفيت زندكى كل \\
\hline
\end{tabular}

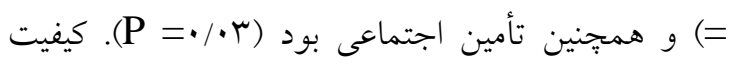
زندكى افراد با بيمه سلامت نيز به طور معنى دارى كمتر از

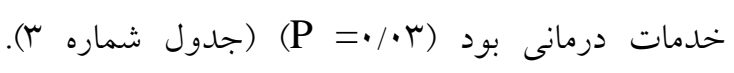
اضطراب مرك با نسبت بيمار ارتباط معنىدار آمارى داشته و ميانخين نمره اضطر اب در فرزندان به طور

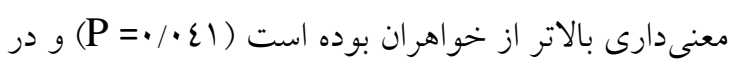

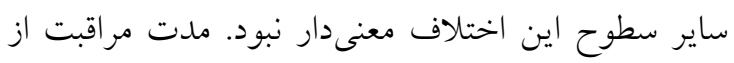

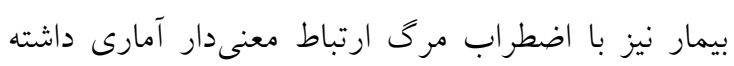

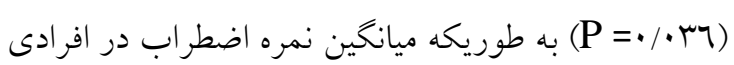

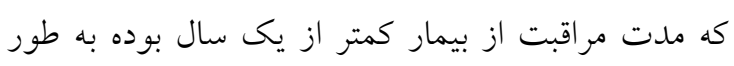

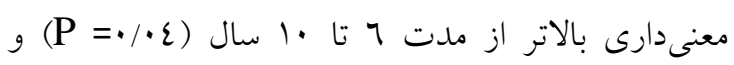

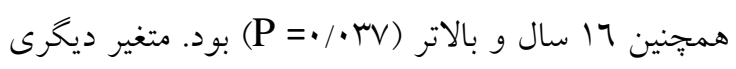

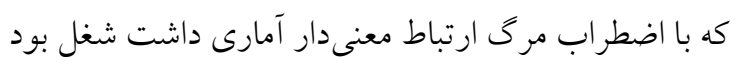

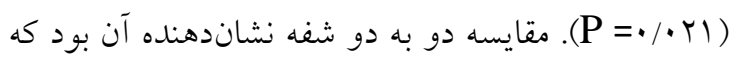

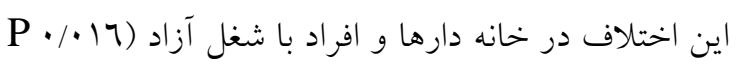

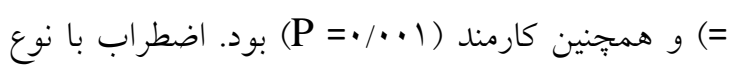

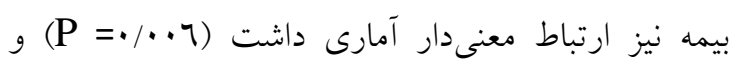
مقايسه دو به دو شفه نشاندهنده آن بود كه اضطراب مرى لئي در افرادى كه داراى بيمه خدمات درمانى بودند به طور

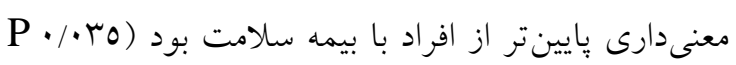

كيفيت زندكى با سن ارتباط معنىدار آمارى داشت

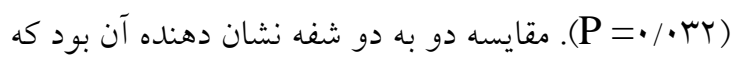

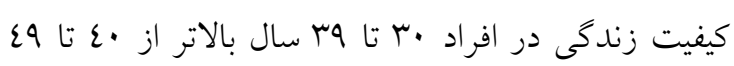

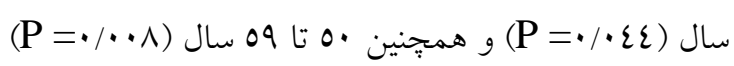

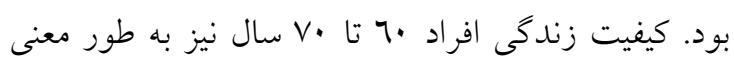

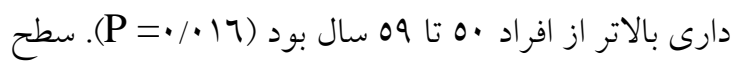
تحصيلات متغير ديخرى بود كه با كيفيت زندكى ارتباط

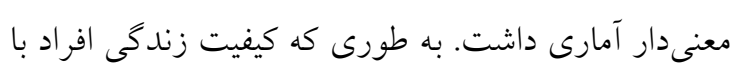
تحصيلات دانشخاهى به طور معنىدارى بالاتر از زيردييلم

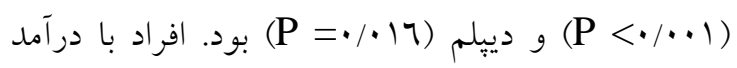
ضعيف نيز كيفيت زندكى بايين ترى نسبت به افراد با كيفيت

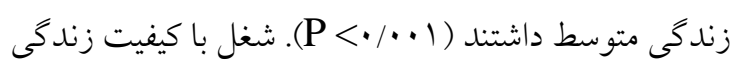

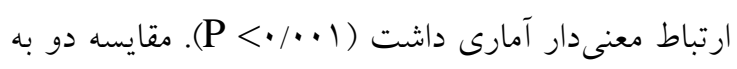
دو شفه نشان داد كه كيفيت زندگى در افراد خانهدار به طور

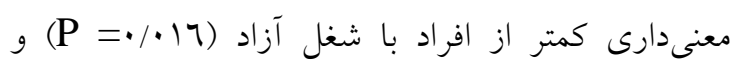

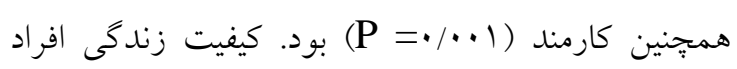

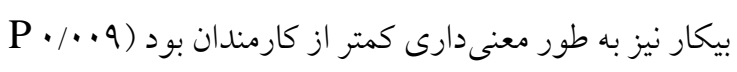

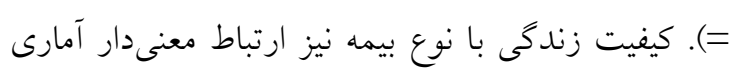

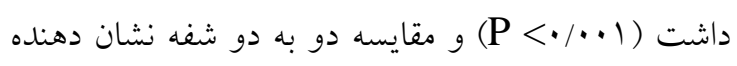
آن بود كه كيفيت زندگى در افرادى كه بيمه نداشتند به طور

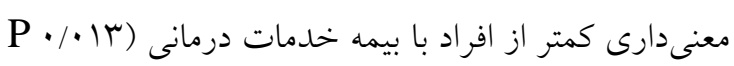


جدول شماره س: شاخصهاى عددى كيفيت زندكى و ارتباط آن با مشخصات جمعيت شناختى در مراقبين افراد مبتلا به مالتيبل اسكلروزيس

\begin{tabular}{|c|c|c|c|c|c|c|c|c|}
\hline \multicolumn{3}{|c|}{ اضطراب مرى } & \multicolumn{3}{|c|}{ كيفيت زندگى } & \multirow[b]{2}{*}{ تعداد } & \multirow{2}{*}{\multicolumn{2}{|c|}{ مشخصات جمعيت شناختى }} \\
\hline نتايج آزمون & انحراف معيار & ميانغين & نتايج آزمون & انحراف معيار & ميانكين & & & \\
\hline & ro/r & $7 / 0$ & $F=r / V \cdot r$ & $1 r / 97$ & $00 / 9 r$ & $\varepsilon$. & $r \cdot>$ & \\
\hline $\mathrm{F}=\cdot / \mathrm{uq}$ & $\varepsilon / \tau V$ & $0 / 27$ & $P=\cdot / \cdot r r$ & $1 T / 91$ & $0 N / 14$ & vi & $r q-r$. & سن (سال) \\
\hline \multirow{3}{*}{$\mathrm{P}=\cdot / 7$} & $r / \mu r$ & $7 / \mu V$ & & $11 / 99$ & $O T / \Sigma q$ & ¿o & $\varepsilon q-\varepsilon$. & \\
\hline & $\varepsilon / .0$ & $0 / \Lambda \Lambda$ & & $11 / \mathrm{AV}$ & $\varepsilon q / . r$ & ro & $09-0$. & \\
\hline & $\varepsilon / \cdot r$ & $0 / 0 T$ & & $1 \varepsilon / \Gamma r$ & $09 / 1$ & 19 & $V \cdot-7 \cdot$ & \\
\hline$t=1 / \pi r a d f=191$ & $\varepsilon / T r$ & $T / r r$ & $t=1 / 97 \pi$ & $1 \varepsilon / 09$ & or/Th & $11 \mathrm{~V}$ & مرد & جنسيت \\
\hline $\mathrm{P}=\cdot / / 71$ & $r / l \varepsilon$ & $0 / 0$ & $\mathrm{df}=191 \mathrm{P}=. / .01$ & $\mid \varepsilon / \Lambda \Lambda$ & $O V / \Lambda \varepsilon$ & $\lambda \mu$ & زن & \\
\hline \multirow{7}{*}{$\begin{array}{l}F=r / \Lambda \vee q \\
P=\bullet / \bullet l\end{array}$} & $r / 7 r$ & $T / Y \Lambda$ & $F=1 / 9 \mathrm{~V}$ & $1 T / T r$ & $7 r / \varepsilon V$ & $v$ & يدر & \\
\hline & $0 / T Y$ & $1 / \pi 0$ & $P=\cdot / \cdot V r$ & $17 / 97$ & $0.1 \mathrm{M}$ & $r \cdot$ & مادر & \\
\hline & $r / 9 r$ & $\varepsilon$ & & $11 / 99$ & $7 \cdot / V$ & rl & خواهر & \\
\hline & r/or & VNr & & IN/AY & $07 / 29$ & rI & برادر & نسبت با بيمار \\
\hline & $r / r \mu$ & $0 / 7 Y$ & & $1 \varepsilon / 0 \mathrm{~V}$ & $07 / \varepsilon$ & $\wedge \cdot$ & ل الممسر & \\
\hline & $\varepsilon / 0$ & $\mathrm{~V} / \mathrm{V} \varepsilon$ & & $\mathrm{V} / \mathrm{\Lambda}$ & $\{9 / \varepsilon\rceil$ & TV & 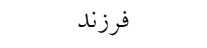 & \\
\hline & $r / r$ & $T / 1 T$ & & $17 / V \wedge$ & $0\{/ 07$ & $r \varepsilon$ & 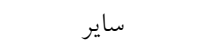 & \\
\hline \multirow{5}{*}{$\begin{array}{l}F=r / \neg r \\
P=\cdot / \cdot r r\end{array}$} & r/07 & $V / \varepsilon T$ & $F=1 / \varepsilon r_{0}$ & $\mathrm{~V} / 0$ & $\{V / 91$ & $1 \varepsilon$ & كمتر از يك & \\
\hline & $r / 7 r$ & $\tau / r \varepsilon$ & $\mathrm{P}=\cdot / T r V$ & $1 r / 9 r$ & $00 / 7 \mathrm{~V}$ & $\varepsilon \varepsilon$ & r-o & مدت مراقبت \\
\hline & $r / \varepsilon$ & $7 / 71$ & & $\mathrm{IV} / \varepsilon$ & $0 \mathrm{~V} / \cdot 0$ & 00 & $7-1$. & از بيمار (سال) \\
\hline & $r / 9 \Lambda$ & $0 / \varepsilon \varepsilon$ & & $10 / 00$ & $O r / \Lambda \varepsilon$ & $\varepsilon 9$ & $11-10$ & \\
\hline & $\varepsilon / 10$ & $\varepsilon / 00$ & & $1 Y / \cdot 0$ & $0 V / 7$ & $\mu_{\Lambda}$ & 17 و بيشتر & \\
\hline \multirow{3}{*}{$\begin{array}{l}\mathrm{F}=1 / 0 \varepsilon 1 \\
\mathrm{P}=\cdot / T \mid V\end{array}$} & $r / V 7$ & $0 / 9 \varepsilon$ & $F=q / 7 \varepsilon r$ & II/Ar & $0 . / r$. & 09 & زير دييلم & \\
\hline & $\varepsilon / 7 \varepsilon$ & $T / \varepsilon V$ & $\mathrm{P}<\bullet / \cdot \cdot 1$ & $|r / T|$ & $0 \varepsilon / 19$ & VT & دييلم & تحصيلات \\
\hline & T/VO & orr & & $17 / \wedge 7$ & $71 / Y 1$ & $u$ & دانشگاهى & \\
\hline $\mathrm{t}=1 / 07 \mathrm{~T} \quad \mathrm{df}=191$ & $r / r q$ & $7 / \wedge$. & $\mathrm{t}=\varepsilon / \Gamma T \Gamma \quad \mathrm{df}=190$ & $10 / 11$ & $\varepsilon\urcorner / \wedge$. & $\varepsilon$. & ضعيف & درآمد \\
\hline $\mathrm{P}=\cdot / T$ & $r / 9 r$ & $O N \varepsilon$ & $\mathrm{P}<\cdot / \cdot \cdot \mid$ & $1 r / 97$ & $0 V / 00$ & $10 \mathrm{~V}$ & متوسط & \\
\hline $\mathrm{t}=\cdot / \pi r$ df $=191$ & $\varepsilon / \cdot r$ & $\varepsilon / \wedge 9$ & $\mathrm{t}=\cdot / 791 \quad \mathrm{df}=197$ & $1 \varepsilon / 9 \varepsilon$ & $00 / 11$ & 117 & شخصى & نوع مالكيت \\
\hline$P=\cdot / 1 / 9$ & r/OV & $T \cdot r$ & $\mathrm{P}=\cdot / \mathrm{VI}$ & $10 / .1$ & OO/AY & $\wedge \cdot$ & اجاره اى & منزل \\
\hline$F=r / \mu r$ & $r / 9$. & $0 / 70$ & $\mathrm{~F}=\wedge / 10 \mathrm{~V}$ & $|r / \Sigma|$ & $09 / 10$ & $M$ & كارمند & \\
\hline \multirow[t]{3}{*}{$\mathrm{P}=\cdot / \cdot r \mid$} & $r / \varepsilon$. & $0 / 7 r$ & $\mathrm{P}<\bullet / \bullet \cdot$ & $17 / 9 r$ & $O V / \varepsilon V$ & 00 & آزاد & | ا شغل \\
\hline & $r / 01$ & $7 / \cdot r$ & & Ir/or & $\{\Lambda / 1\}$ & r7 & بيكار & \\
\hline & $\varepsilon / \bullet \wedge$ & V/AT & & $1 \varepsilon / T_{0}$ & $\varepsilon V / \cdot V$ & $r$. & خانه دار & \\
\hline$F=r / \cdots 1$ & $r / 9 r$ & $0, r 7$ & $\mathrm{~F}=\cdot / r q 1$ & $1 r / I V$ & $0 \varepsilon / 1$. & 0. & مجرد & \\
\hline \multirow[t]{2}{*}{$\mathrm{P}=\cdot / \cdot$ or } & $r / 00$ & $7 / 20$ & $\mathrm{P}=\cdot / 7 \mathrm{VV}$ & $1 \varepsilon / 90$ & $00 / 0 r$ & $|r|$ & متأهل & وضعيت تأهل \\
\hline & 0 & $\varepsilon / r \mu$ & & $1 V / 9 \varepsilon$ & $0 V / 77$ & IV & مطلقه / بيوه & \\
\hline$F=r / \neg \wedge \vee$ & $r / 乏 \wedge$ & $O N V$ & $\mathrm{~F}=\Delta / \mathrm{\varepsilon} \wedge$ & $11 / 20$ & $\varepsilon r / T r$ & Ir & ن ندارد & \\
\hline \multirow[t]{4}{*}{$P=\cdot / \cdot \cdot 7$} & $r / 29$ & $\varepsilon / \varepsilon \wedge$ & $\mathrm{P}<\bullet / \bullet \cdot 1$ & $1 \varepsilon / \varepsilon r$ & $7 \cdot / \varepsilon V$ & r & خدمات درمانى & \\
\hline & $r / 17$ & $\varepsilon$ & & $17 / \varepsilon r$ & $09 / 79$ & $1 \varepsilon$ & نيروهاى مسلح & بيمه \\
\hline & $r / \mu$. & VNT & & $11 / 91$ & $\varepsilon 9 / \Gamma_{0}$ & $\varepsilon$. & بيمه سلامت & \\
\hline & $\varepsilon / 1$. & $7 / 1 \Lambda$ & & $1 \varepsilon / V q$ & $0 V / 1$ & 1.1 & بيمه تامين اجتماعى & \\
\hline$t=\cdot / \cdot r l$ & $r / \wedge r$ & $0 / 9 \varepsilon$ & $\mathrm{t}=r / \cdots 9 \mathrm{df}=191$ & $1 \varepsilon / \wedge 9$ & $0 \mathrm{r} / .0$ & $1 \cdot 1$ & بله & به تنهايى \\
\hline $\mathrm{df}=191$ & r/AF & $\Delta / 9 \Delta$ & $\mathrm{P}=\cdot / \cdot\{\rceil$ & $1 F / 09$ & $\Delta V / T q$ & 91 & خير & مراقبت كردن \\
\hline $\mathrm{P}=\cdot / 9 \wedge \mu$ & & & & & & & & از بيمار \\
\hline
\end{tabular}


كه اختلاف اضطر اب مرك در زن و مرد ممكن است مربوط به شرايط اجتماعى و فرهنگ متفاوت باشد.

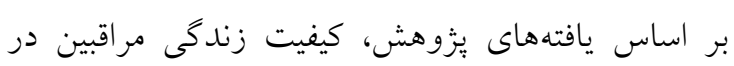

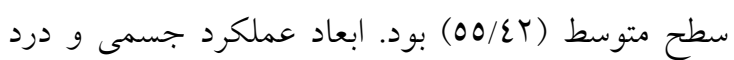
نشان دهنده كيفيت زندگى خوب بوسط بود. بعد عملكرد جسمانى مهمترين مؤلفه در افزايش يا كاهش كيفيت زندكى مراقبين است. كيفيت زندكى مراقبين در ابعاد محدوديتهاى ايفاى نقش ناشى از مشكلات هيجانى،

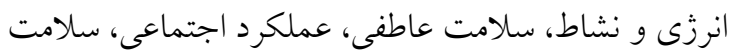
عمومى، سلامت جسمى و روانى، كيفيت متوسط و بعد محدوديتهاى ايفاى بايين بود. در مطالعه رهنما كيفيت زندگى در مراقبين بيماران Or/V MS بود. به عبارتى ديخر

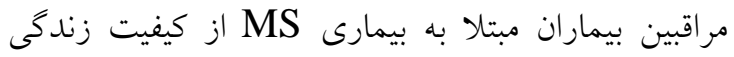

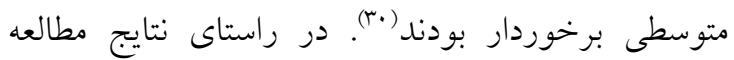

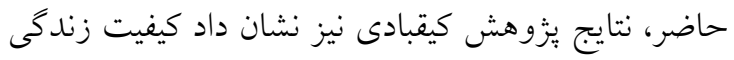

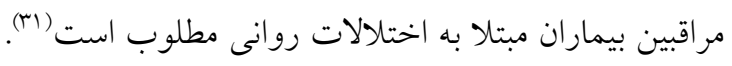

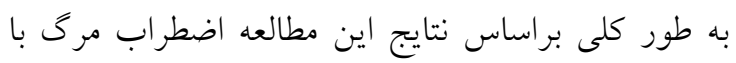

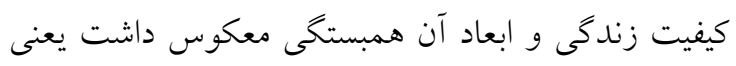
با افزايش اضطراب مرگ، كيفيت زندكى و ابعاد آن كاهش ونش

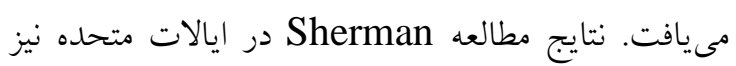

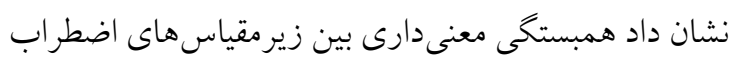

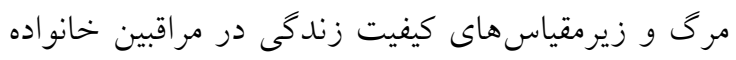

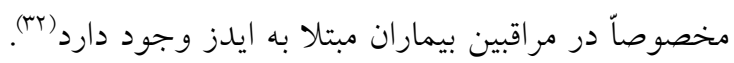

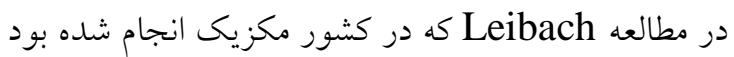
يافتهها نشان داد سلامت روانى مر اقبين در شر ايطى كه بيمار كيفيت زندكى و سلامت عمومى بايين ترى دارد بسيار بايين

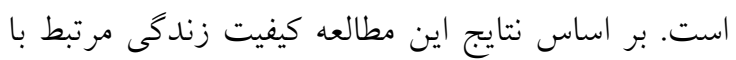

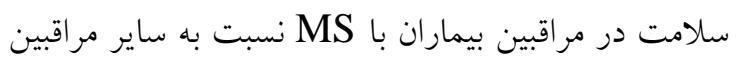
هايينتر است و VT درصد از مراقبين در صورتى كه از لحاظ روانى به وضعيت وخيم ترى برسند ديخر قادر به ادامه

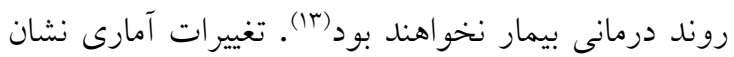
دادند كيفيت زندگى مرتبط با سلامت به تنهايى عامل 19

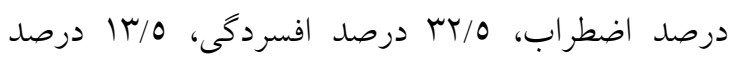

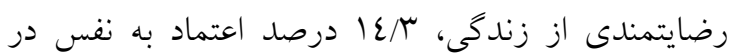

\section{بحث و نتيجه كيرى}

براساس نتايج اين مطالعه اكثريت مراقبين اضطراب مرى دئ دابن

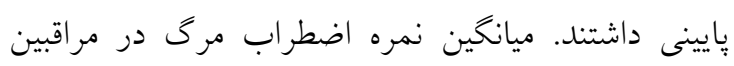

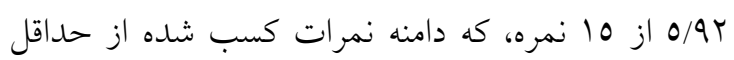

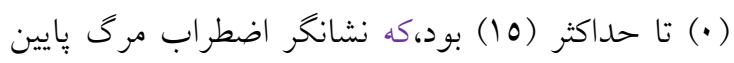
مراقبين مىباشد. Bobo و همكاران ميانگين اضطراب

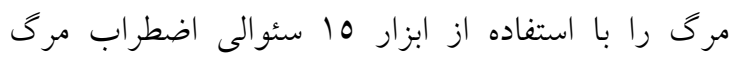

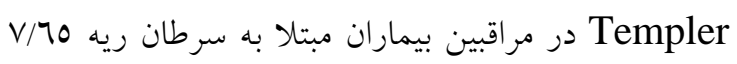

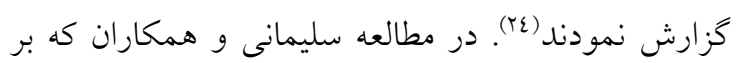

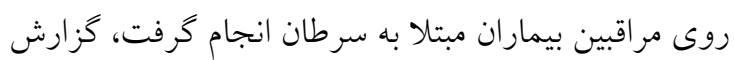

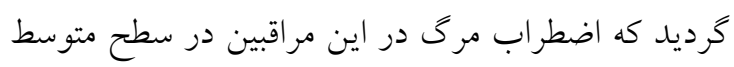
است و ميانخين نمره اضطراب مرگ در مراقبين بيماران

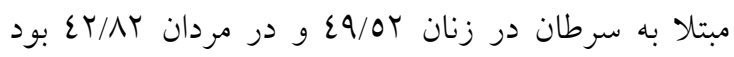

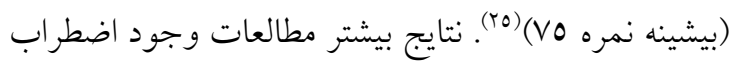

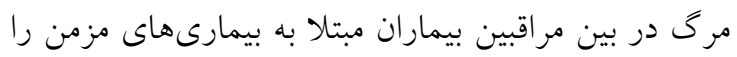

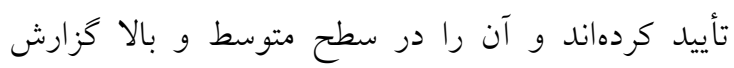

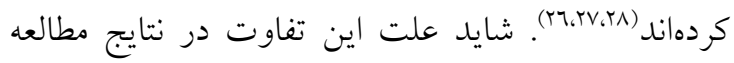
حاضر با ساير مطالعات به نوع بيمارى در بيماران تحت

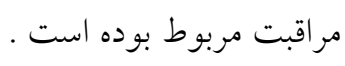
اضطراب مرى با نسبت بيمار ارتباط معنىدار آمارى داشته برده

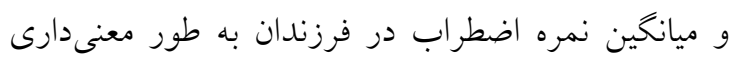

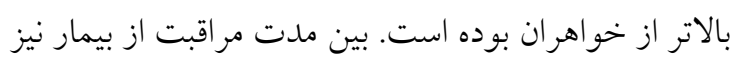

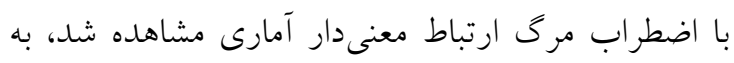

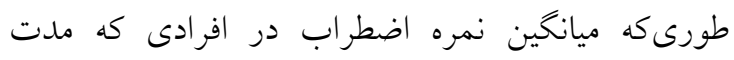
مراقبت بيماريشان كمتر از يكى سال بوده به طور معنى دارى لهري

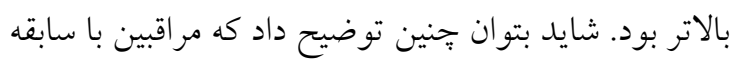

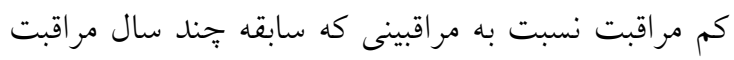

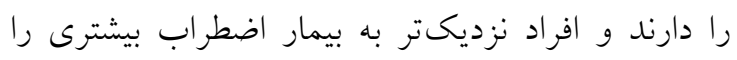

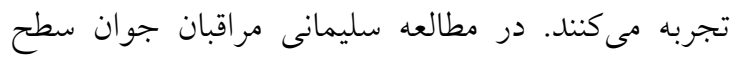
بالاترى از اضطراب مرى را گزارش كردند، علاوه بر اين،

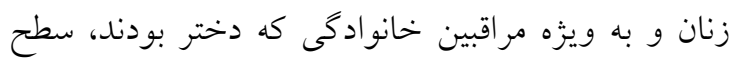

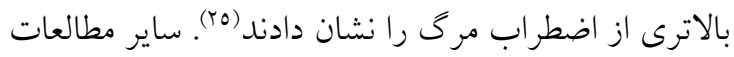

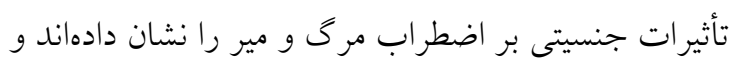

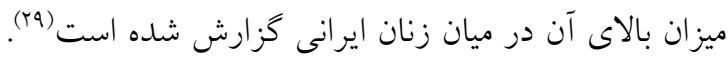


شرايط روانى نمونهاى مورد يزوهش حين تكميل

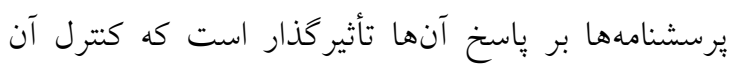

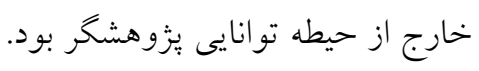
با توجه به نتايج مطالعه حاضر و مشاهده ارتباط معنى بردار

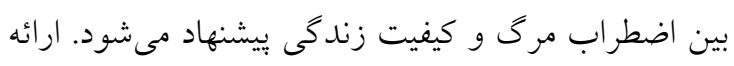

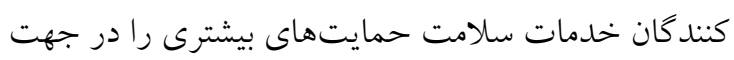
رفع مشكلات و كاهش اضطراب مرى در مراقبين بيماران

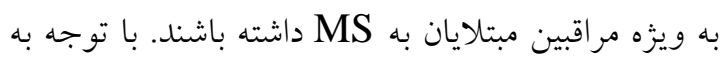

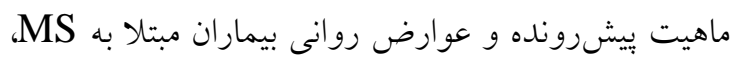

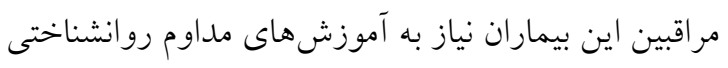

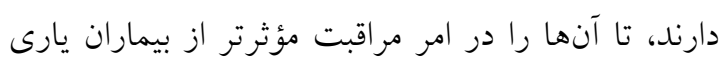

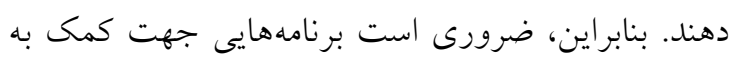

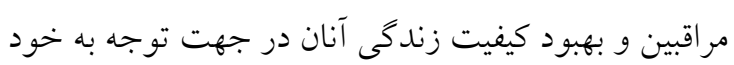
و نيازهايشان تشكيل شود.

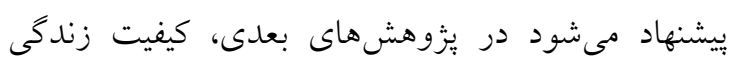

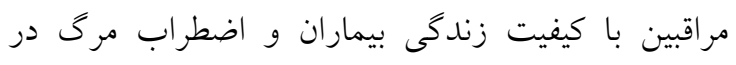

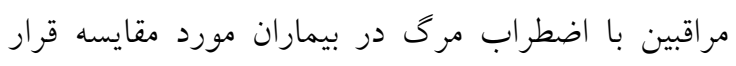
كيرد.

تعارض منافع: از نظر نويسنده تعارض منافعى در اين يزوهش وجود ندارد.

\section{تقدير و تشكر}

نتايج اين مقاله بر كرفته از بِيان نامه كارشناسى ارشد

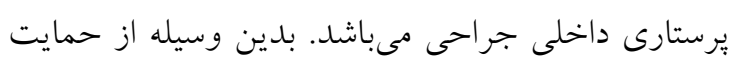

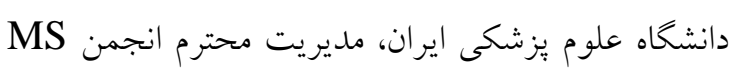

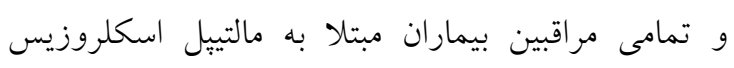

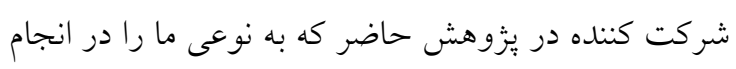

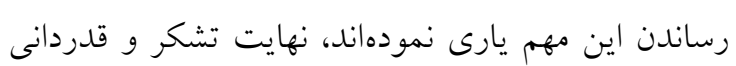
را داريم.
مراقبين است. اين يافته حاكى از اين است كه ارتباطى قوى

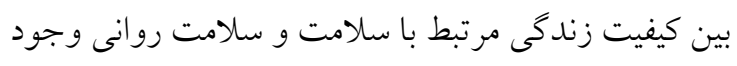

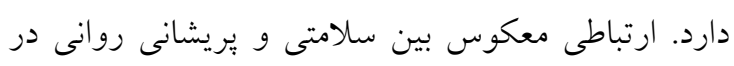

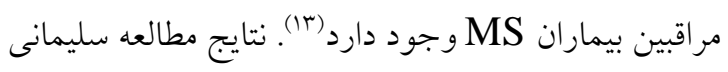

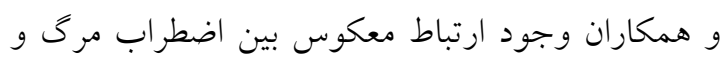

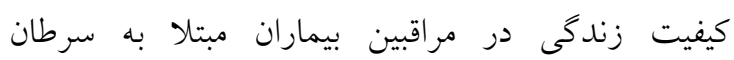

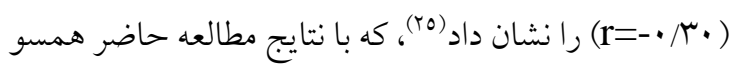

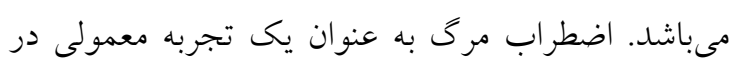
هنخام يادآورى تهديد مرى افز ايش مى يابد (10).

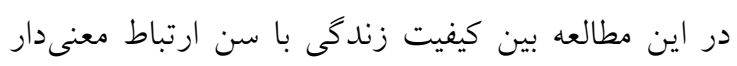

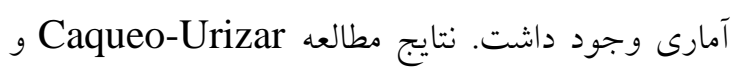

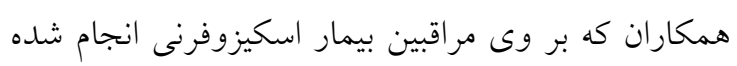

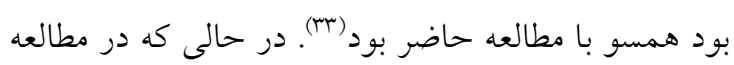

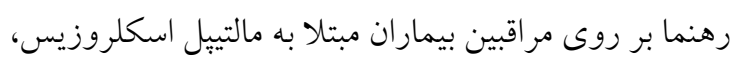

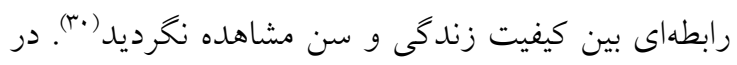

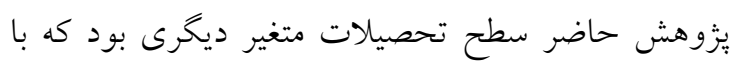

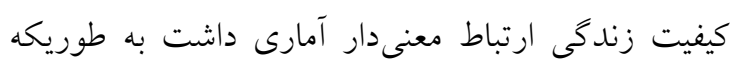

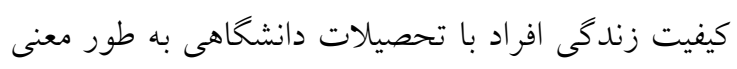

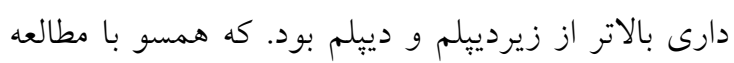

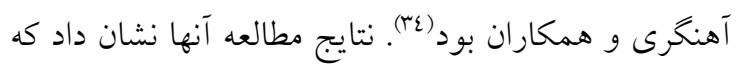
با افزايش سطح تحصيلات، كيفيت زندكى مراقبين بهتر

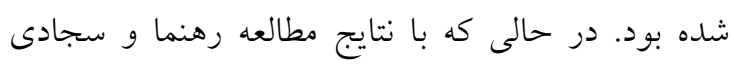

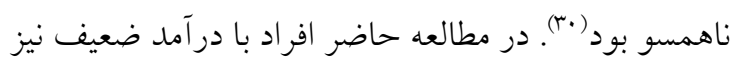

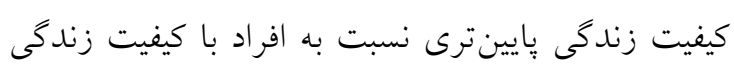

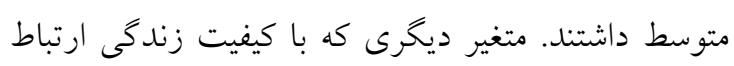

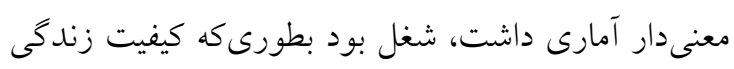

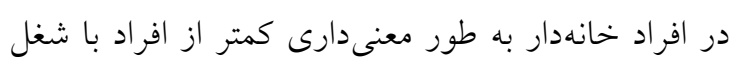

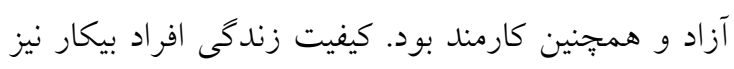

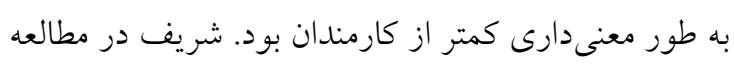
خود نشان داد كه كيفيت زندگى خانو ادههاى داراى بيمار

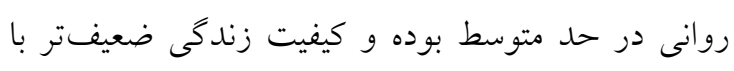
جنسيت زن، شغل خانهدارى و انزواى اجتماعى ارتباط داشت (ro) 


\section{References}

1. Lazar RB, editor. Principles of neurologic rehabilitation. McGraw-Hill; 1998.

2. Hauser S, Josephson S. Harrison's Neurology in Clinical Medicine, 3E. McGraw-Hill Education; 2013.

3. Browne P, Chandraratna D, Angood C, Tremlett H, Baker C, Taylor BV, Thompson AJ. Atlas of multiple sclerosis 2013: a growing global problem with widespread inequity. Neurology. 2014;83(11):1022-4.

4. MSIF. What is MS? 2018 (cited 2019 -5 -22). Available from: https://www.msif.org/aboutms/what-is-ms/.

5. Azami M, YektaKooshali MH, Shohani M, Khorshidi A, Mahmudi L. Epidemiology of multiple sclerosis in Iran: A systematic review and meta-analysis. PloS one. 2019;14(4):e0214738.

6. Buchanan RJ, Radin D, Chakravorty BJ, Tyry T. Informal care giving to more disabled people with multiple sclerosis. Disability and rehabilitation. 2009;31(15):1244-56.

7. Denno MS, Gillard PJ, Graham GD, DiBonaventura MD, Goren A, Varon SF, Zorowitz R. Anxiety and depression associated with caregiver burden in caregivers of stroke survivors with spasticity. Arch Phys Med Rehab. 2013;94(9):1731-6.

8. Figved N, Myhr KM, Larsen JP, Aarsland D. Caregiver burden in multiple sclerosis: the impact of neuropsychiatric symptoms. J Neurol Neurosurg Psychiatry. 2007;78(10):1097-102.

9. Gupta S, Goren A, Phillips AL, Stewart M. Self-reported burden among caregivers of patients with multiple sclerosis. Int J MS Care. 2012;14(4):179-87.

10. Dayapoğlu N, Tan M. The care burden and social support levels of caregivers of patients with multiple sclerosis Nursing-Original article.

11. Mitchell LA, Hirdes J, Poss JW, Slegers-Boyd C, Caldarelli H, Martin L. Informal caregivers of clients with neurological conditions: profiles, patterns and risk factors for distress from a home care prevalence study. BMC Health Serv Res. 2015;15(1):350.

12. Nia SH, Hojjati H, Nazari R, Qorbani M, Akhoondzade G. The effect of prayer on mental health of hemodialysis patients referring to Imam Reza Hospital in Amol City. IJCCN. 2012;5:29-34. [Persian]

13. Leibach GG, Stern M, Arelis AA, Islas MA, Barajas BV. Mental Health and Health-Related Quality of Life in Multiple Sclerosis Caregivers in Mexico. International journal of MS care. 2016 Jan;18(1):19-26.

14. Krapp K. Activities of Daily Living Evaluation., Encyclopedia of Nursing \& Allied Health. Gale Group. Inc: USA. 2002.

15. Belsky J. The psychology of aging: Theory, research, and interventions: Brooks/Cole Pub.

16. Bastani F, Farnood F, HAGHANI H. Evaluation of Death Anxiety in Elderly Patients With Cancer Undergoing Chemotherapy. Journal of Client-Centered Nursing Care. 2016;2(3):153-60. [Persian]

17. Salehi F, Mohsenzade F, Arefi M. Prevalence of death anxiety in patients with breast cancer in Kermanshah, 2015. Iranian Quarterly Journal Of Breast Disease. 2016;8(4): 34-40. [Persian]

18. Masoudzadeh A, Setareh J, Mohammadpour RA. A survey of death anxiety among personnel of a hospital in Sari. Journal of Mazandaran University of Medical Sciences. 2008;18(67):84-90. [Persian]

19. Hemmatpoor B, Gholami AL, Parnian S, Seyedoshohadaee M. The Effect of Life Skills Training on the Self-Management of Patients with Multiple Sclerosis. J Med Life. 2018;11(4):387.

20. Templer DI. The construction and validation of a death anxiety scale. J Gen Psychol. 1970;82(2):165-77.

21. Rajabi GR, Begdeli Z, Naderi Z. Psychometric properties of the Persian version of Death Depression Scale among nurses. Death studies. 2015;39(6):342-6. 
22. Ware Jr JE, Sherbourne CD. The MOS 36-item short-form health survey (SF-36): I. Conceptual framework and item selection. Medical care. 1992 1:473-83.

23. Montazeri A, Goshtasebi A, Vahdaninia M, Gandek B. The Short Form Health Survey (SF-36): translation and validation study of the Iranian version. Quality of life research. 2005;14(3):875-82.

24. Lau BH, Wong DF, Fung YL, Zhou J, Chan CL, Chow AY. Facing death alone or together? Investigating the interdependence of death anxiety, dysfunctional attitudes, and quality of life in patient-caregiver dyads confronting lung cancer. Psycho-oncology. 2018;27(8):2045-51.

25. Soleimani MA, Lehto RH, Negarandeh R, Bahrami N, Chan YH. Death anxiety and quality of life in Iranian caregivers of patients with cancer. Cancer nursing. 2017;40(1):E1-0.

26. Elizarrarás-Rivas J, Vargas-Mendoza JE, Mayoral-García M, Matadamas-Zarate C, ElizarrarásCruz A, Taylor M, Agho K. Psychological response of family members of patients hospitalised for influenza A/H1N1 in Oaxaca, Mexico. BMC psychiatry. 2010;10(1):104.

27. Götze H, Brähler E, Gansera L, Schnabel A, Gottschalk-Fleischer A, Köhler N. Anxiety, depression and quality of life in family caregivers of palliative cancer patients during home care and after the patient's death. Eur J Cancer Care. 2018;27(2):e12606.

28. Grabler M, Weyen U, Juckel G, Tegenthoff M, Mavrogiorgou-Juckel P. Death anxiety and depression in amyotrophic lateral sclerosis patients and their primary caregivers. Front Neurol. 2018;9:1035.

29. Bahrami N, Moradi M, Soleimani MA, Kalantari Z, Hosseini F. Death anxiety and its relationship with quality of life in women with cancer. Iran Journal of Nursing. 2013;26(82):51-61. [Persian]

30. Rahnema S, Baghersad Z, Shirazi M, Chitsaz A, Etemedifar M. Association between Family Caregivers'quality of Life and Psychological Capital of the Patients with Multiple Sclerosis. Journal Of Isfahan Medical School (I.U.M.S). 2016;34(377):335-40. [Persian]

31. Keighobadi S, Neishabouri M, Haghighi N, Sadeghi T. Assessment of Quality of life in Caregivers of Patients with Mental Disorder in Fatemie hospitals of Semnan city. Advances in Nursing \& Midwifery. 2013;23(79):36-44. [Persian]

32. Sherman DW, Norman R, McSherry CB. A comparison of death anxiety and quality of life of patients with advanced cancer or AIDS and their family caregivers. J Assoc Nurses AIDS Care. 2010;21(2):99-112.

33. Caqueo-Urízar A, Gutiérrez-Maldonado J. Burden of care in families of patients with schizophrenia. Quality of Life Research. 2006;15(4):719-24.

34. Ahangari M, Kamali M, Arjmand Hesabi M. Quality of elderly's life in Tehran senile culture house clubs. Iranian Journal of Ageing. 2007;2(1):182-9. [Persain]

35. Sharif Ghaziani Z, Ebadollahi Chanzanegh H, Fallahi Kheshtmasjedi M, Baghaie M. Quality of Life and Its Associated Factors among Mental PatientsFamilies. Journal of Health and Care. 2015;17(2):166-77. [Persian] 